J. Reprod. Fert. (1974) 39, 425-427

\title{
THE SPONTANEOUS MOTILITY OF THE HUMAN FALLOPIAN TUBE
}

\author{
ANN PARKER,* FRANCES N. RUSH AND K. J. DENNIS \\ Department of Human Reproduction and Obstetrics, \\ University of Southampton, Southampton SO1 $6 H U$
}

(Received 19th February 1974)

\begin{abstract}
Summary. The spontaneous motility of ampullary and isthmic regions of Fallopian tubes from women at different stages of the ovarian cycle was examined using three parameters, frequency, intensity and activity units.

Differences in motility were demonstrated between sites and between some of the stages of the cycle.

The activity of the ampulla was greater than that of the isthmus during the proliferative and secretory stages. The isthmic region had constant activity throughout the cycle, but the ampulla was less active during the puerperium.
\end{abstract}

The factors controlling oviducal motility are not yet understood and no clearcut motility pattern has been shown to be optimal for ovum transport. Previous studies on human Fallopian tubes in vitro have produced contradictory observations. The following is an investigation, using isometric recording methods similar to those described by Sandberg, Ingelman-Sundberg, Lindfren \& Ryden (1960), of the spontaneous motility of Fallopian tubes during various phases of the menstrual cycle and in the early puerperium.

Fallopian tubes were obtained either at the time of abdominal hysterectomy or at sterilization and only those with a normal microscopic appearance were used. In ovulating women, the tubes were classified according to the phase of the cycle by taking into account the woman's menstrual pattern and the endometrial histology.

The tube was placed immediately into Krebs' solution with the following composition: $\mathrm{NaCl}, 69 \mathrm{~g} ; 10 \% \mathrm{KCl}, 35 \mathrm{ml} ; 10 \% \mathrm{MgSO}_{4} .7 \mathrm{H}_{2} \mathrm{O}, 29 \mathrm{ml}$; $10 \% \mathrm{KH}_{2} \mathrm{PO}_{4}, 16 \mathrm{ml}$; glucose, $20 \mathrm{~g} ; \mathrm{NaHCO}_{3}, 21 \mathrm{~g} ; 1 \mathrm{~m}-\mathrm{CaCl}_{2}, 25.2 \mathrm{ml}$, made up to 10 litres with distilled water. As soon as possible, a length of tube (approximately $2 \mathrm{~cm}$ ) was taken from either the isthmic or ampullary end of the specimen and dissected free of its peritoneal covering with the underlying connective tissue. It was transferred to a $10-\mathrm{ml}$ organ-bath filled with Krebs' solution and kept at a temperature of $37^{\circ} \mathrm{C}$ by means of a thermostatically controlled water-bath. A mixture of $95 \% \mathrm{O}_{2}$ and $5 \% \mathrm{CO}_{2}$ was continuously bubbled through the bath. The tube was connected to a strain gauge and tension changes were shown on a recorder. A small resting tension of between

* Present address: Gynaecological Department, Lister General Hospital, Stevenage, Herts. 
4 and $6 \mathrm{~g}$ was placed on the preparation and a period of about $30 \mathrm{~min}$ allowed for the spontaneous motility to become established as a constant wave form. The Krebs' solution was replaced at 10-min intervals.

The parameters measured from the recorder tracings were: (1) frequency, i.e. number of contractions during a standard time of three minutes; (2) average intensity, i.e. average height of all contractions over $1 \mathrm{~mm}$ during the standard time; (3) activity units, the product of average intensity and frequency. The results were subjected to statistical analysis and a significant difference was taken as being twice the standard error of the difference of the means.

The data were obtained from the following samples:

\begin{tabular}{lcc}
\multicolumn{1}{c}{ Stage of cycle } & $\begin{array}{c}\text { Isthmic } \\
\text { region }\end{array}$ & $\begin{array}{c}\text { Ampullary } \\
\text { region }\end{array}$ \\
Proliferative phase & 16 & 17 \\
Secretory phase & 14 & 13 \\
Puerperium & 17 & 17
\end{tabular}
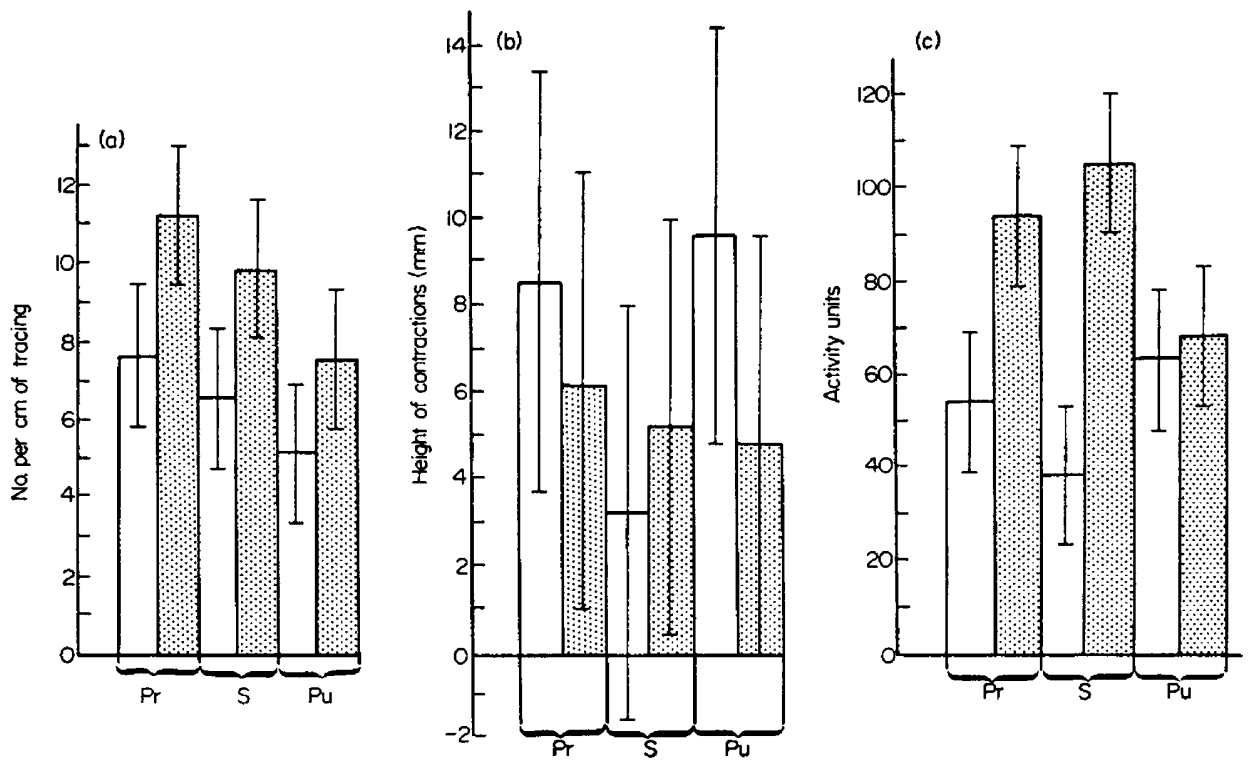

TEXT-FIG. 1. The spontaneous motility of the ampullary (stippled columns) and isthmic (open columns) regions of the human Fallopian tube in three phases of the reproductive cycle $(\mathrm{Pr}=$ proliferative; $\mathrm{S}=$ secretory; $\mathrm{Pu}=$ puerperal $)$. Vertical bars represent twice the standard error. (a) Frequency of the contractions during the standard time of $3 \mathrm{~min}$. (b) Average intensity of contractions during the standard time of $3 \mathrm{~min}$. (c) Activity units (product of the average intensity and frequency) during the standard time of $3 \mathrm{~min}$.

In all tubes, the ampullary region contracted at a greater frequency than the isthmic part (Text-fig. 1a). The puerperal tube contracted less frequently than a tube from an ovulating woman although the difference was not always statistically significant.

The intensity of contractions showed no such difference between parts of the same tube from any normal environment (Text-fig. 1b). The isthmic part 
of the tube during the secretory phase, however, had a lower average intensity than during either the proliferative phase or the puerperium. This difference was not seen between the ampullary regions.

The values for the activity units of tubes during the proliferative and secretory phases were significantly higher in ampullary than in isthmic regions (Text-fig. 1c). The activity of the isthmic part stayed relatively constant throughout the three cycle phases but the ampullary region of the tube during the puerperium showed less activity than the same region during either the secretory or proliferative phases, although the difference was only significant during the secretory phase.

The results suggest that there are definite differences in oviducal muscular activity between the ampullary and isthmic regions of the tube and between tubes under different hormonal conditions. These findings are in direct contrast to those of Sandberg et al. (1960) who used isotonic methods. Study of total muscle activity however can be misleading and the functional meaning of our observations is hard to surmise. It is interesting that in recent work by SicaBlanco, Rozada, Remedio, Hendricks \& Alvarez (1970) and Sica-Blanco, Cibels, Remedio, Rozada \& Gil (1971), in which motility was monitored in vivo by inserting polythene catheters into the tubal lumen, the intensity of the contractions was found to be generally higher at the isthmic level. Apart from this observation, very great variability in tubal contractility of the oviduct is an important factor in the ascent of spermatozoa and/or descent of the egg (as it seems logical that it should be), its mechanism does not seem to be by means of a peristaltic wave which predictably changes its direction according to the normal changes of the ovarian cycle.

Further work on tubal muscle response to various drugs has been undertaken and will be the subject of subsequent papers.

We should like to thank Dr M. Gardner for carrying out the statistical analysis.

\section{REFERENCES}

SAndberg, F., Ingelman-Sundberg, A., Lindfren, L. \& Ryden, G. (1960) In vitro studies of the motility of the human Fallopian tube. Acta obstet. gynaec. scand. 39, 506.

Sica-Blanco, Y., Cibels, L. A., Remedio, M. R., Rozada, H. \& Gil, B. E. (1971) Isthmic and ampullar contractility of the human oviduct in vivo. Am. F. Obstet. Gynec. 11, 91.

Sica-Blanco, Y., Rozada, H., Remedio, M. R., Hendricks, C. H. \& Alvarez, H. (1970) Human tubal motility in vivo. Am. F. Obstet. Gynec. 106, 79. 